\title{
OPENING SOLILOQUY IN LIEU OF A PREFACE
}

The purpose of this book is to do away with the "and" in its title.

Expression and truth are classic opposites in Western thought. Expression refers to states of mind, not states of being. If we follow J. L. Austin's procedure of classifying communicative acts by the way they are judged, then expression is faithful or unfaithful. Expressive acts may be true or false to their source, but they are neither true nor false. They are thus not what Austin calls constative, but neither are they what he calls performative, that is, utterances that succeed or fail at doing something in being uttered. The only thing expressive acts do is be what they are.

Or so we classically think-mistakenly. The classic view of expression is neither consistent with contemporary accounts of how the brain works nor able to stand up to philosophical investigation in the manner of Wittgenstein. This book seeks to perform that investigation with some help from Wittgenstein himself and from his scattered remarks on what is classically the most purely expressive of the arts and (thus) the one most removed from truth. Not by chance, that art is music.

The purpose of this book is to express the truth in expression: to perform, "happily," as Austin would say, the marriage of truth and expression and to state, truly, that what expression expresses is or may be truth.

But if so, so what? One has to ask.

The first decade of the twenty-first century has been so troubled as to revive old questions about the value of either practicing or studying the arts of expression-questions the first half of the twentieth century had posed all too acutely. The problem has been compounded since by digital technology, which renders all forms of expression both evanescent and infinitely malleable, and by the proliferation of media-manipulated modes of expression 
that induce a routine skepticism, even cynicism, about all expressive acts. In this context, an absorption in expression or in its study may seem not only socially irresponsible but also intellectually bankrupt. Acts of expression may still give pleasure and promise truth, but only, it may seem, on condition that we do not look too closely at either the acts or the offerings.

It is a measure of how difficult things have become that any promise to resolve these questions directly would (and perhaps should) sound both pompous and self-deceived. So I will do no more than suggest that a care for expression, for the culture of expression and the truth of expression, commits one to certain values that many may wish to preserve, even against steep odds and strong skepticism. To borrow the approach of my chief interlocutor in this text, I will seek mostly to show those values rather than to say what they are: to make my case primarily by practice, not proclamation.

The practice begins with the form of the book: a classic arch. (The image of the arch is both musical and architectural.) A pair of extended duos with Wittgenstein on expression in music frames a pair of reflections on the relationship between melody and speech, which in turn frames a central series of investigations of the enveloping terms expression and truth. This design aims to perform the book's overarching thesis by forming a truthful expression of it: a shape intimating the classical hermeneutic images of circle, spiral, and arc, and going these one better by taking the hemispheric pattern as a gateway, the frame of a threshold through which understanding may pass to and fro.

As this description suggests, Expression and Truth seeks not only to think truly about expression but also to think with it. True to its thesis, however, the book's expressive, free-flowing mode of exposition is guided by conceptual claims it hopes to make credible, one per chapter, to wit:

"Wittgenstein, Music, and the Aroma of Coffee": Expression is description. "Speaking Melody": Expression is unvoicing.

"Expression and Truth": Expression is cognition.

"Melodic Speech": Expression is envoicing.

"Wittgenstein, Music, and the Tone of Crystal": Expression is reply.

To make this fivefold claim is to embrace a worldview in which sensing, perceiving, feeling, and understanding form neither a continuum nor a system of oppositions but a lacework movement within the medium of expression. Hence the book's subtitle: The forms of cognition become what they are by participating in the music of knowledge. 